\title{
Annals of the National Academy of Medical Sciences (India) in a New Incarnation
}

\author{
Saroj Chooramani Gopal ${ }^{1}$ \\ 1Department of Pediatric Surgery, Institute of Medical Sciences, \\ Banaras Hindu University, Varanasi, Uttar Pradesh, India \\ Ann Natl Acad Med Sci (India) 2019;55:1-2
}

It is a turning point in the journey of the National Academy of Medical Sciences (India), which is collaborating with the world renowned Thieme Medical Publishers. This partnership would not only energize our periodical but also help in making a significant impact on the national and international readership consisting of health scientists and professionals. By joining Thieme Medical Publishers, the Academy looks forward to globalization of Indian medical research and disseminating the information related to the initiatives of Ministry of Health and Family development to every corner of the country and also to an international level.

The academy wishes to inform that the new website of the journal will be www.thieme.com/anams. We wish to encourage potential authors to submit their articles at www.manuscriptmanager.net/anams.

On this occasion, it would be indeed worthwhile to inform readers about the remarkable history of the Academy, its objectives and its official journal.

The Government of India decided to establish a separate Department of Health Research in the erstwhile Ministry of Health $(\mathrm{MoH})$, which is now the Ministry of Health and Family Welfare (MoHFW), and authorized it to establish institutions for Continuing Medical Education (CME) in the country. Thereafter, a society named "Indian Academy of Medical Sciences" was founded under the Department of Health Research in MoHFW, akin to the prestigious Indian Council of Medical Research (ICMR). The Memorandum of Association, at the time of the registration of the academy as the "Indian Academy of Medical Sciences," was signed by Drs. B.K. Anand, Col. Sangham Lal, K. L. Wig, Gen. Amir Chand, S. K. Sen, V. Ramalingaswami, B.L. Taneja, and R. Viswanathan. It was registered on April 21, 1961, with the Registrar of Societies, Delhi as the "Indian Academy of Medical Sciences."
Dr. Rajendra Prasad, the

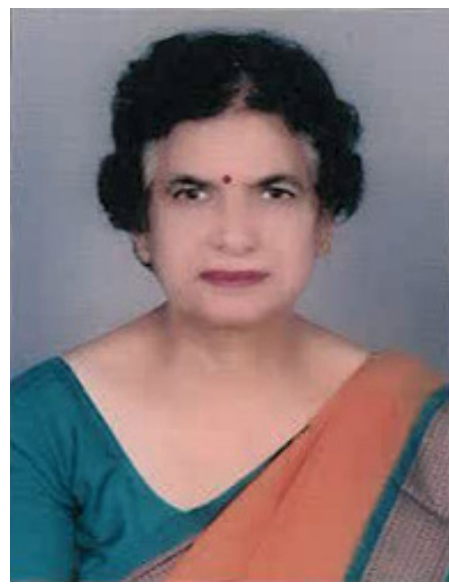

first president of India,

Saroj Chooramani Gopal

The first prime minister of India, Shri Jawaharlal Nehru, formally inaugurated the academy at the Sapru House on December 19, 1961. To commemorate the occasion, he was bestowed with the Honorary Fellowship of the Academy.

On November 16, 1976, the name of the society was changed to "National Academy of Medical Sciences (India)." The new name was registered at the office of the Registrar of Societies, Delhi Administration, New Delhi.

Since its inception, the objectives of the National Academy of Medical Sciences (India) are as follows:

1. Promotion of knowledge of medical sciences in India and its practical application to problems plaguing national welfare.

2. Recognizing and encouraging merit across all branches of medical sciences.

3. To ensure coordination between medical and other scientific academies, societies, associations, institutions, as well as government medical and scientific departments and services.

4. To seek help and cooperation of international agencies and national bodies of other countries.

5. To act through properly constituted National Committees in order to deal with medical scientific subjects, and undertake medical scientific work of national and international importance as the Academy may be called upon to perform by the public and the Government.

6. To publish such proceedings, journals, memoirs, transactions, and other publications as may be found desirable.

C2019 National Academy of Medical Sciences (India)
License terms

() (1) $\Theta \circledast$

\section{Address for correspondence} Saroj Chooramani Gopal, (President NAMS), MS, MCh, FAMS, Department of Pediatric Surgery, Institute of Medical Sciences, Banaras Hindu University, B5/F2, Meera Colony, Varanasi-221005, Uttar Pradesh, India (e-mail: sarojchooramani@gmail.com).
DOI https://doi.org/ 10.1055/s-0039-1697582 ISSN 0379-038X. 


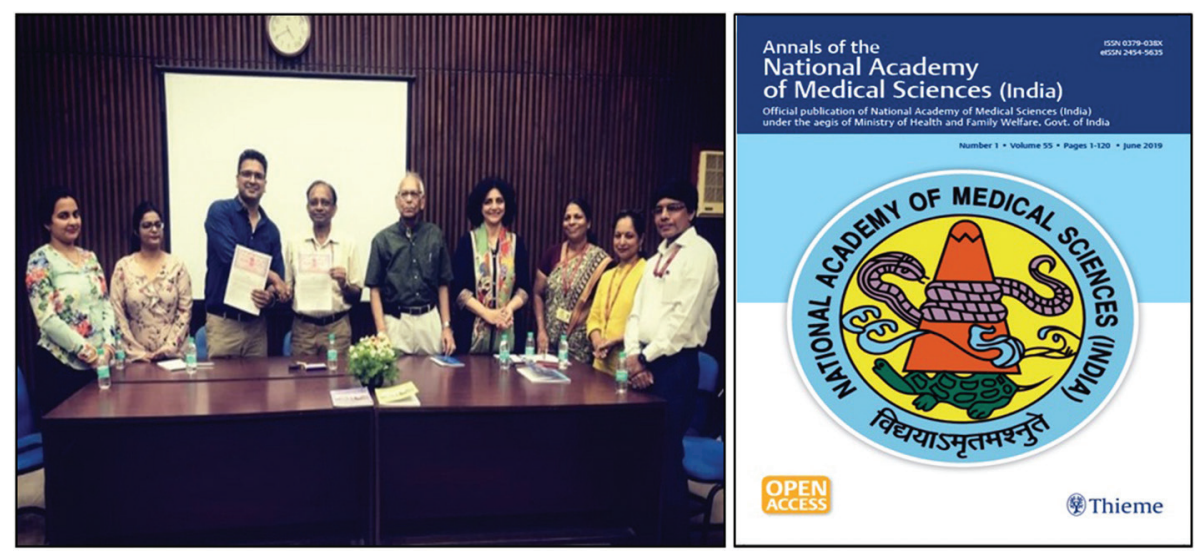

From extreme left to right: Team Thieme along with Dr. Sunny Duttagupta (third from the left), Dr. Deep N. Srivastava (Secretary NAMS and Editor ANAMS), Dr. KK Sharma (Advisor NAMS and Editor ANAMS), Dr. Shilpa Sharma, and members of the Editorial Team, NAMS.

7. To promote and maintain a liaison between medicinal and other sciences by way of different associations and societies, and establish inter-association/inter-society partnership and collaboration.

8. To develop pattern(s) of high-level postgraduate examinations, at the all-India basis across various disciplines of medical sciences, to ensure a uniform standard of postgraduate medical qualifications, for which appropriate machinery would be required to become operational.

9. To secure and manage funds and endowments for the promotion of the objectives of the academy.

10. To undertake any other steps that may assist in, be conducive to, or be necessary for the fulfilment of the above-mentioned aims and objectives of the academy.

In 1975, the working group appointed by the Government of India recommended the setting up of a National Board of Examinations (NBE), and the responsibility of conducting high-level postgraduate examinations on an all-India basis across various disciplines of medicine was entrusted to the academy. The President of the academy was designated as the president of the NBE.

NBE, since its inception, functioned in close association with the National Academy of Medical Sciences (India), which was presided over by the president of the academy from 1975 to 1982 . However, the two bodies were separated as legal entities by the MoHFW in March, 1982. The board was reconstituted and the president of the National Academy of Medical Sciences (India), who had been till then the president of the NBE, was included as one of the members of the board. Till August 1982, the postgraduate medical qualification of "MAMS" was awarded through the examination conducted by the academy. Subsequently, from February 1983 onward, the "MAMS" examinations were conducted by the NBE; instead of "MAMS," the "Diplomate of NBE (DNB)" was awarded. By a decision taken by the NAMS Council, the DNB holders of NBE are eligible to become members of NAMS and will be provided with the Scroll of "MNAMS."

The academy conducts an Annual Conference, NAMSCON, in different parts of the country to commemorate its activities as well as disseminate recent advances in medical and health sciences by inviting a wider audience of health professionals on a regional basis. Besides, the NAMS, to maintain its mandate given by the MoHFW, acts as a promoting agency for CME to advocate "Knowledge to Action." To accomplish this, the academy provides financial support to not only organize the CMEs but also allocate financial grants to the junior and middle level bio-medical scientists to hone their research and professional skills by learning through hands-on experience in the chosen institution of eminence in the country. On their return to their native institutions, they are more equipped to take care of the health needs of their patients and health seekers.

The academy also recognizes merit and awards fellowships (FAMS) to senior scientists with an exemplary and consistent track record, and membership (MAMS) to junior and mid-level scientists among the biomedical and health professionals alike. The process of selection is conducted keeping in mind very stringent criteria, and domains are vetted at multiple levels of screening by senior experts in the field.

This year, the official journal of the academy, the Annals has received a facelift to reach the height of a new horizon. We hope the readers would appreciate this change and contribute to the growth of the journal and the academy in achieving its objectives. We sincerely look forward to receiving content from enthusiastic researchers and clinicians. Supported by Thieme Medical Publishers, the Academy under the aegis of Ministry of Health and Family Welfare will continue to effectively contribute towards healthcare initiatives and clinical research in the country.

\section{Conflict of Interest}

None declared.

\section{Acknowledgment}

The help rendered by Dr. Shilpa Sharma, MNAMS, Associate Professor, Department of Pediatric Surgery, AIIMS, New Delhi by way of providing significant inputs in preparing this editorial is highly appreciated and acknowledged. 